\title{
New Structures in Neurology: Palliative Care for Neurological Patients
}

\section{() $\circledast \Theta$}

Authors

Heidrun Golla ${ }^{1}$, Gereon R. Fink ${ }^{2,3}$, Roman Rolke ${ }^{4}$, Stefan Lorenzl5, 6, 7, Markus Ebke ${ }^{8}$, Thomas Montag ${ }^{1}$, Ralf Gold ${ }^{9}$, Gereon Nelles ${ }^{10}$, Carsten Eggers ${ }^{11}$, Raymond Voltz ${ }^{1}$, 12, 13, 14

Affiliations

1 Department of Palliative Medicine, University Hospital of Cologne

2 Department of Neurology, University Hospital of Cologne

3 Cognitive Neurosciences, Institute of Neurosciences and Medicine (INM-3), Research Center Jülich

4 Department of Palliative Medicine, Faculty of Medicine of RWTH Aachen University

5 Institute of Nursing Science and Practice, Paracelsus Medical University, Salzburg, Austria

6 Department of Neurology and Palliative Medicine, Hospital Agatharied GmbH, Hausham

7 Department of Palliative Medicine, University Hospital of Munich LMU

8 Neurological rehabilitation center (NRZ) Bad Salzuflen, Bad Salzuflen

9 Department of Neurology, University Hospital, St. Josef Hospital, Faculty of Medicine, Ruhr University Bochum

10 NeuroMed Campus Hohenlind, Joint Practice of Neurology, Special Pain Therapy, Rehabilitation, Cologne

11 Department of Neurology, University Hospital of Giessen and Marburg, Marburg

12 Center for Integrated Oncology Cologne/Bonn (CIO), Cologne

13 Center for Clinical Studies, Cologne University Hospital (ZKS), Cologne

14 Center for Health Services Research, Faculty of Medicine, University of Cologne

Key words

palliative care, neurological diseases, healthcare structures

Bibliography

DOI https://doi.org/10.1055/s-0043-108438

Neurology International Open 2017; 1: E117-E126

(c) Georg Thieme Verlag KG Stuttgart · New York ISSN 2511-1795

Correspondence

PD Dr. med. Heidrun Golla

Department of Palliative Medicine

University Hospital of Cologne
Kerpener Straße 62

50937 Cologne

Germany

heidrun.golla@uk-koeln.de

\section{ABSTRACT}

Although patients with incurable neurological diseases suffer from a variety of distressing symptoms and may die from their neurological condition and associated complications, palliative and hospice care for these patients to date remains rare. Initial estimates indicate that on average $10 \%$ of all patients suffering from a neurological disease need palliative and hospice care. However, within German neurology departments, only few physicians (on average 1.3/department) and nurses (on average 2.2./department) are specialized in palliative and hospice care and only about $3 \%$ of patients cared for in palliative or hospice care structures suffer from neurological diseases (in contrast to the approximately $80 \%$ of patients suffering from oncological diseases). This rather low number is due to the gradual increase in the awareness of palliative and hospice care needs for neurological patients and a currently predominant supply of oncological patients in palliative and hospice care structures that are primarily aimed at these patients. Correspondingly, the special aspects of neurological patients are currently not adequately addressed in the palliative training curricula of healthcare professionals. Rather, patients with advanced neurological conditions are medically cared for by general practitioners and by the existing inpatient and outpatient neurology structures, which may also offer sub-specialty services. Consequently, adequate care for severely affected neurological patients becomes difficult as soon as these patients are hardly able to visit these structures because home-based specialist treatment is currently rendered and financed only to a limited degree. Novel yet to date rare approaches, mostly of international origin, suggest that these patients may benefit from specialized home-based services, combining neurological and palliative care expertise. At present, data that characterizes the situation of neuro-palliative care in Germany remains scarce. In addition to the already known supply gaps (e. g., low rate of neurologists trained in palliative medicine as well as of nurses working in neurology 
trained in palliative care, lack of consideration of the specific (care) needs of neurological patients in general and specialized palliative and hospice care structures, few available home-based outpatient specialists) research is a prerequisite to identify current gaps in palliative care of neurological patients in more detail and how these might be overcome in the future.
This article presents an overview of current palliative care of patients suffering from neurological diseases. After a brief introduction to the epidemiological figures on the need for palliative care vs. the care reality in these patient groups in Germany, typical palliative care symptoms and needs as well as the extent to which they are addressed are described. The healthcare structures in which patients in need of neuropalliative care are currently cared for in Germany are described in detail as well as the possibilities for integrating existing palliative and hospice care structures into their care. After an overview of research results on innovative neuropalliative care services, considerations are presented on how neuropalliative care in Germany could be improved.

\section{Palliative Care of Neurological Patients: Need vs. Reality}

In a survey [1], the participating German chief physicians of neurological institutions estimated that an average of $10 \%$ of their neurological patients had palliative care needs as defined by the World Health Organization (WHO) [2], particularly patients with the following diagnoses: brain metastases, glioblastoma and other primary brain tumors; amyotrophic lateral sclerosis (ALS), idiopathic or atypical Parkinson's syndrome incl. multiple system atrophy (MSA) and corticobasal degeneration or Huntington's disease. The need for palliative care was also noted in patients with dementia syndromes, stroke, multiple sclerosis (MS) and traumatic brain injury. $12.1 \%$ of the chief physicians surveyed and an average of 1.3 physicians and 2.2 nurses of the respective institution had received additional training in palliative care with a view toward implementing palliative aspects into neurological treatment. According to the annual hospice and palliative care survey (HOPE), in 2015, 74.4$88.6 \%$ of the patients cared for in palliative and hospice care structures were reported to suffer from malignant neoplasms. 0-3.6\% of the patients cared for in palliative and hospice care structures suffered from a primary disease of the central nervous system [3], although the prevalence of such diagnoses suggests a much greater scope of care. The neurological chief physicians surveyed [1] cited in most cases cardiovascular diseases, infections, and underlying malignant diseases as the cause of death in their patients, whereas underlying neurological diseases were regarded as uncommon (9\%). According to the Federal Statistics Office [4], of the total 868,356 deaths in Germany in 2014, the 10 most frequent causes of death included: heart disease (chronic ischemic heart disease (8\%), acute myocardial infarct (5.5\%), cardiac insufficiency (5.1\%), hypertensive cardiac disease $(2.6 \%)$ ); diseases of the lung (other chronic obstructive lung disease (3.1\%)), malignant diseases (lung and bronchial cancer (5.2\%), breast cancer $(2.1 \%)$, colon cancer (1.9\%)); and neurological pathologies such as unspecified dementia $(2.9 \%)$ or stroke not specified as hemorrhage or infarction (1.9\%). The literature also indicates that numerous neurological diseases shorten life expectancy due to their fatal course (e. g., paralysis of the respiratory muscules in neuromuscular diseases) or accompanying complications (e. g., accidents, falls) that can cause premature death [5-7].

\section{Palliative Care Symptoms and Needs of Patients with Neurological Diseases}

Many neurological patients, such as those with primary brain tumors, advanced MS, ALS, and idiopathic or atypical Parkinson's disease, suffer from debilitating symptoms and participation disturbances at the physical, psychosocial, and spiritual level and are therefore predestined for palliative care [2,8-19]. The symptoms of neurologically ill patients are similar to those of oncology patients, such as increased incidence of pain, fatigue, shortness of breath, and constipation, even though the severity and frequency may differ. Other symptoms specific to diseases of the peripheral or central nervous systems may also be present, e. g., the occurrence of (painful) spasticity, paralyses, vegetative disorders, dysphagia, speech impairments, epileptic seizures, myclonus, and neuropsychological and neuropsychiatric impairments. The high intensity of nursing care and family caregiver burden as well as ethical and psychosocial issues are particularly challenging in the care of these patients [8-20]. Patients with primary brain tumors, for example, were shown to suffer much less frequently from the typical palliative care symptoms included in the HOPE palliative care outcome mesauremnet, such as bodily pain, nausea, vomiting, constipation, and lack of appetite, than other patients requiring palliative care. In contrast, scores were especially high in the categories "Needs assistance with activities of daily life," "Disorientation/confusion," "Excessive strain on family/environment," along with the high intensity of nursing care [20]. As glioblastoma progresses, palliative care symptoms, the need for support, fears of family members, and the subjective perception that life is no longer worth living increase [17]. Utilizing HOPE as outcome measurement [10] obvious differences between oncology patients and those with severe MS could be identified in terms of: symptom burden, intensity of nursing care, degree of disability, type of medication and type of measures carried out over the course of the disease. The protracted course of the disease led to more comorbidities. Diseases of the psyche, the urogenital tract and the musculoskeletal system more frequently occurred in patients with severe MS than in oncology patients. Furthermore, more patients suffering from severe MS [10] lived in nursing homes (21\%) than oncology patients (10\%). In ALS patients, symptoms that result from the unrelenting progressive paresis of the various muscle groups predominate. They include dysphagia with sialorrhea, risk of aspiration and the question of placing a percutaneous endoscopic gastrostomy (PEG) tube, limited ability to speak and the need for alternative forms of communication, insufficiency of the respirato- 
ry muscles with resulting shortness of breath and anxiety and the issue of drug therapy and/or ventilation and secretion management to alleviate these symptoms. All these examples illustrate problems that rarely occur in this form and constellation in oncology patients with palliative care needs [13-15]. In patients with idiopathic or atypical Parkinson's disease, not only do the extrapyramidal motor symptoms play a special role in addition to the classic palliative care symptoms like pain. Other issues emerge, such as the administration of Parkinson's medication in the advanced disease stages (dysphagia, fluctuating drug responses, drug-induced delirium) and challenges from the development of Parkinson's-associated dementia [11-13].

\section{Discrepancy Between the Demand for and Implementation of Palliative and Hospice Care for Patients with Neurological Diseases}

Although the examples cited do illustrate that many neurological patients need palliative and hospice care, the terms palliative and hospice are currently associated mainly with dying cancer patients [21-23]. Additionally, some healthcare professionals believe that neurological patients would not in any way benefit from palliative and hospice care and would not die from their neurological illness $[21,24,25]$. This assumption may be one reason why so few patients with neurological diseases are treated in palliative and hospice care structures [3]. Another reason may be that the structures of the modern palliative and hospice care movement developed primarily to care for oncology patients, so fewer patients with primary neurological diseases and their special and often difficult symptom constellations are represented [26]. Another reason it may be difficult to care for neurological patients in palliative and hospice care structures is that neurological diseases often have a chronic course with longer disease trajectories than is usually the case with many oncology patients. This occasionally makes it more difficult to recognize end-of-life signs [27].

Palliative and hospice care for patients with neurological diseases requires special training with respect to the specific symptoms and disease courses. Healthcare professionals must acquire the appropriate expertise, and structural modifications to palliative and hospice care structures may be required as well.

\section{To Date, in Which Existing Healthcare Structures Have Neurological Patients in Need of Palliative Care Been Treated in Germany?}

\section{Neurological structures}

In the Federal Republic of Germany there are a total of 1717 practicing neurologists (office-based) to treat the wide variety of acute and chronic neurological disorders. Of those physicians, 1299 are independent and 418 on staff. In addition, 1931 practicing "Nervenärzte" (a combined medical specialization in neurology and psychiatry which cannot be obtained in this form any longer) work exclusively with outpatients. Inpatient treatment is available at 358 acute care neurology clinics, 143 neurology rehabilitation clinics, 115 specialist clinics, and 43 university hospitals with additional special outpatient clinics for numerous and even rare neurological diseases (source: German Association for Neurology (DGN), [28]). In this system, neurological patients receive medical diagnostics and treatment according to high standards and according to guidelines. Difficulties in neurological care often emerge in case of advanced stages of neurological diseases when these patients are hardly able to visit their attending physicians, outpatient clinics and hospitals and are forced to rely on care at home or in a nursing home. Few neurologists make house calls, if at all most likely in nursing homes, although precise data is lacking. Even supplementary at-home co-therapy from physical, occupational and speech therapists is often difficult to organize, and not just in rural areas. This is especially true for psychotherapeutic support.

\section{Examples of neuropalliative care options in Germany}

In Germany, some regional and some national structures that address neurological and palliative care concerns have been developed for some progressive neurological diseases. One of them is the multiprofessional palliative care service of the Marianne Strauss Clinic in Kempfenhausen (specialist clinic for MS), which provides care to patients in advanced stages of MS in accordance with the specifications of the Bavarian Professional Program for Palliative Care in Hospitals (EDSS >8) [10]. After a pilot phase [29] in cooperation with the German Multiple Sclerosis Society (DMSG), there is now a national telephone hotline for severely affected MS patients and their families to answer questions on palliative and hospice care and its structures. The telephone consulting hotline represents a low-threshold service that is also available to healthcare providers. The information given by the hotline helps to spread the palliative and hospice care concept within a patient group that until now has had little contact with the palliative and hospice care structures. This service helps to facilitate that contact. The established, closely cooperating ALS centers in Germany aim to improve clinical care of ALS patients struggling with numerous palliative care symptoms and issues. The "Ambulanzpartner" [Outpatient Partner] Project has an important role in this endeavor [14, 30]. Through case management linked to an Internet-based management portal, Ambulanzpartner supplies ALS patients with adequate resources of every type (e. g., mobility aids, orthoses, communication aids). This assistance is especially important with regard to symptomatic and palliative care of these patients experiencing a progressive irreversible loss of muscle function [14, 30]. The coordinative assistance through case management relieves patients and families, affording them time to cope with the profound changes in their living conditions. The Cologne Parkinson's Network is one example of integrated neurological care of complex Parkinson's patients. Patients receive coordinated treatment from a movement disorder specialist of the University Hospital of Cologne, their attending neurologist, and a Parkinson's nurse who also makes house calls. One important aspect that the current model does not include yet, however, is providing palliative care advice e. g., with respect to advance care planning or palliative care symptomatic treatment in rapidly progressing disease courses.

A few neurological clinics offer "palliative beds" reserved for inpatient care of the most seriously ill neurological patients. Accord- 
ing to the survey previously cited [1], approx. $8 \%$ of the participants indicated having an average of 4.4 "palliative beds" available. Outpatient care of neurological patients is made more difficult when patients are no longer able to visit their neurologists and must rely more on their general practitioners. This is a major challenge for general practitioners in light of the complexity of serious neurological disorders. With respect to questions on palliative and hospice care they can find support in palliative and hospice care structures, which can basically be used by all patients with palliative care needs regardless of their diagnosis [2]. Yet the reality is markedly different: Currently only up to $3.6 \%$ of patients receiving care in these facilities have a primary neurologic disorder [3].

\section{Possibilities of complementary integration of the palliative and hospice care approach and its struc- tures in the care of neurological patients with palliative care needs}

Palliative care is not strictly confined to the dying, but is also appropriate earlier in the disease course, including in connection with disease-modifying therapies. This early integration of palliative care is expressly recommended by the WHO and the American Society for Clinical Oncology (ASCO). Introducing palliative care early on in the course of a progressive, life-threatening disease offers the best possible symptom control, advance care planning, and ultimately well-prepared transition into strictly palliative care. In oncology patients with a variety of disease entities, it was shown that early integration of palliative care improved quality of life [31-33] and even extended survival [31]. For oncology patients, standard operating procedures (SOP) [34] define for different disease entities when palliative care should be introduced. Such SOP do not yet exist for neurological diseases, making it difficult for neurologists - unlike oncologists - to decide when to start palliative care in the treatment process. Depending on the clinical picture, a palliative care approach for neurologically diseased can be envisioned the time of diagnosis (e. g., ALS, glioblastoma) or once prognostically poor symptoms appear, such as dysphagia e. g., with (atypical) Parkinson's disease [27] or after a defined degree of disability (e. g., MS) has been reached [35]. But it is currently unclear whether the duration of a neurological disease alone can be a potential parameter. SOP, that remain to be developed for neurological disorders, would help to consistently integrate the palliative care approach in the care of these patients. This does not in any case need palliative care specialists. Approx. $10 \%$ of patients with palliative care needs require specialized palliative care (SPC). The remaining $90 \%$ of patients with palliative care needs can be treated through general palliative care (GPC) (see $>$ Table 1) [36]). The networking and integration of interfaces in the cross-sector concepts play an important role in both GPC and SPC. Palliative and hospice care structures for both GPC and SPC developed very differently in Germany and are heterogeneous. In spite of substantial progress over recent years, universally consistent and qualitatively equivalent palliative healthcare and support services are still lacking. To acquire GPC skills, discipline-specific curricula based on the criteria of the German Society for Palliative Medicine (DGP) and the German Hospice and Palliative Association (DHPV) are available for the major occupational groups as well as volunteer caregivers. Specialist physicians can complete additional training in palliative care. Once they have acquired the skills in GPC, the different occupational groups are able to treat patients and their families according to the principles of palliative care in their respective fields. However, there is still no uniformly defined healthcare structure in GPC. Universal contractual and regulatory specifications are also lacking. Usually symptoms that require treatment, individual aspects of palliative care nursing, and psychosocial aspects are the areas of focus. Patients requiring GPC treatment often need a low to medium level of palliative care. SPC requires a qualified multi-professional palliative care team available around the clock. These teams work in a variety of care sectors (inpatient, outpatient, semi-residential). SPC is characterized by a particularly high and complex need for care. Specialized outpatient palliative care (SOPC) is rendered to patients whose complex symptoms require particularly extensive palliative care (medical/nursing), and rendering that care requires specific palliative care skills (medical/nursing) and/or special coordination services. The situation is complex if at least one of the following criteria is present: severe pain, serious neurological/psychiatric/psychic symptoms, threatening and agonizing respiratory, cardiac, gastrointestinal or urogenital symptoms or (ex)ulcerating wounds or tumors.

\section{Financing Palliative and Hospice Care}

Financing GPC, SPC, and hospice care is regulated in different ways across the nation. The most important basis for financing outpatient SPC is legal entitlement (SOPC $§ \S 37 \mathrm{~b}$ and $132 \mathrm{~d}$ SGBV) as long as those affected meet the prerequisites previously described. There is no nationally uniform financing framework and therefore the level of remuneration and the underlying scope of services are regulated differently at the state level. It should be noted that the SOPC service provider must be an autonomous legal entity to be able to enter into the corresponding healthcare contracts. SOPC is not within the scope of services that can be charged by an attending physician or a nursing service. The service providers (so-called SOPC teams or palliative care teams) must conclude separate healthcare contracts with the insurers and separately negotiate the scope of services and the level of remuneration. In some states (e. g., North Rhine Westphalia), this task is handled for the physicians by the regional Association of Statutory Health Insurance Physicians or separate SOPC associations (e.g., Hessen). The scope of services and the contract terms are essentially based on the SOPC Directive of the Joint Federal Committee (GBA) [37] and the current recommendations of the National Association of Statutory Health Insurance Funds (GKV-Spitzenverband) for specialized outpatient palliative care [38].

Inpatient SPC is financed within the framework of DRG hospital financing via a separate OPS for palliative care wards nationwide or through per diem nursing charges for the individual hospital for a so-called "special facility." According to the new Hospice and Palliative Care Law (HPG), each hospital can choose one of the $2 \mathrm{fi}$ nancing options, whereby recognition as a special facility must be renewed annually. According to the HPG [39], consulting palliative care services will be DRG-financed in future. This will not be possible nationwide until 2019 and until that time each hospital must individually negotiate payments. 
- Table 1 Forms of general and specialized palliative care [35].

\section{GPC (healthcare professionals working in GPC do not have their main focus in palliative care)}

General outpatient palliative care (GOPC)

GOPC for inpatient elder care

General inpatient palliative care
Treatment of palliative care patients who require a low to medium level of palliative care.

- Provided by physicians and nurses experienced and qualified in palliative care (e. g., general practitioners/ specialists/nurses with appropriate training in palliative care and nursing)

- Cooperation with other service providers of outpatient palliative care, e.g., hospice care services

- Basic requirements: Qualifications, house calls, reachable around-the-clock

- Part of outpatient palliative care

- Provided by nursing staff qualified in palliative care in cooperation with the general practitioners of the residents and/or qualified palliative care physicians

- Is rendered in regular wards and units in hospitals to patients that do not require specialized palliative care in a palliative care ward. Palliative care (medical/nursing) is provided by appropriately trained and qualified personnel in the given department.

- These teams are often supported by a consulting palliative care service that is usually attached to a palliative care ward

\section{SPC (healthcare professionals} working in SPC have their main focus in palliative care)

Specialized outpatient palliative care (SOPC) care

Consulting palliative care services

Palliative care wards

Care of palliative care patients with particularly complex and high care needs.

- Service regulated according to social law

- Rendered by multiprofessional team especially trained in palliative care (medical/nursing)

- Outpatient care of particularly complex palliative care patients with complex symptoms and/or special need for coordination services

- Legal entitlement if prerequisites are met (valid also for patients in nursing homes and integration assistance facilities (per § 37b SGB V))

- Physician's prescription and approval by insurer required

- Supplementary service to GPC and standard care.

- Rendered on special wards and care units (palliative care wards, inpatient hospices) or by consulting palliative care services that support the teams on the non-palliative care wards in clinics

- Personnel working here are appropriately qualified in palliative care (medical/nursing) and work primarily in palliative care

- Specialized, multiprofessional palliative care teams (palliative care nurses and palliative care physicians, at a minimum)

- Often attached to palliative care wards

- Provide specialized palliative care consulting across disciplines in the hospital (e.g., symptom treatment, early integration of palliative care, end-of-life care)

- Specialized facilities integrated into a hospital to care for patients with incurable, life-threatening diseases whose serious symptoms cannot be adequately treated elsewhere

- Goal is to improve or stabilize the disease situation and ultimately discharge, preferably to home

- If discharge is not possible, render end-of-life support to patient and provide appropriate counseling to families, relatives, and friends.

- Qualified palliative care physicians and nurses are available around the clock.

\section{Assigned to GPC and SPC}

Outpatient hospice care services

Inpatient hospices
- Volunteer groups of trained hospice care volunteers

- Coordination by a (full-time) hospice care coordinator

- Support and daily help services for serious, incurable diseases and consulting on all matters related to palliative and hospice care

- Psychosocial support during the dying and grief process.

- Often assumption of coordination and management tasks in the regional network

- Separate facilities, independent of hospitals and nursing homes, for the critically ill who live and are cared for there until death when at-home palliative care is no longer possible and hospital treatment is not necessary.

- Nursing care by nurses specialized in palliative care.

- Medical care by general practitioners and/or general or specialized palliative care physicians.

- Volunteer hospice care support is also a basic component of hospice care.
There is currently no financial framework for either inpatient or outpatient GPC. Different regional models have developed over recent years and in individual states they are universally available. These include the QPA (qualified palliative care physician) contracts and the palliative care contract in North Rhine Westphalia. Several changes will result in the wake of the implementation of the HPC in the coming years, and it remains to be seen whether uniform healthcare structures comparable with SPC will emerge. The ex- 
pected modifications to the Federal Collective Agreement will be crucial for outpatient care by physicians, as will changes to the German Federal Joint Committee guidelines for outpatient nursing care provided in the home. GPC will be developed and financed primarily as an integrative component of the existing care structures. The extent to which separate characteristics of process and structural quality will be defined as a financing prerequisite in care contracts and legal requirements should be noted. The corresponding contract structures in North Rhine Westphalia are examples.

Many GPC and SPC contracts require a cooperation with outpatient hospice care services as a structural prerequisite for invoicing of services. It should be noted that outpatient hospice care work is funded by insurers separately from the financing of services for outand inpatient healthcare. § 39a SGB V (Social Code Book V) and the corresponding framework agreement [40] are the basis for this. Funding of hospice care services is handled annually in a regulated procedure and ensures payment for the material costs necessary for volunteer end-of-life care and the personnel costs for coordination. In the new HPG, hospice care services can also include endof-life care in hospitals in their subsidy application. To this end, many hospice care services enter into appropriate cooperation agreements in order to regulate the substantive cooperation ( Table 1).

\section{The New Act to Improve Hospice and Palliative Care in Germany (HPG)}

The new HPG [39] that took effect on December 8, 2015 aims to strengthen hospice and palliative care in Germany. The law defines deadlines by which the individual provisions must be implemented. The law stipulates the following main provisions: 1) palliative care is an explicit component of standard care in the statutory health insurance; 2 ) concrete form will be given to the individual palliative care benefits for home nursing services; 3 ) specialized outpatient palliative care in rural areas will be expanded; 4) financial basis for inpatient child and adult hospices will be improved by raising the per diem with insurance funds assuming $95 \%$ of the associated costs; 5) financial position of outpatient hospice care services will be improved through adequate consideration of personnel and material costs. The focus of hospice care services with respect to family grief counseling and the work in nursing homes will be strengthened; furthermore, hospitals will be entitled to commission outpatient hospice care services. 6) Terminal care will become an explicit component of the social long-term care insurance's mandate; 7) for separate palliative care wards, hospital-specific fees can be agreed with the third-party payers; 8) new billing options will be created for the inpatient consulting palliative care service. Under the new OPS code 8-98 h, such care can now be billed as "specialized palliative combination therapy by a consulting palliative care service." What is unique is that now the time actually spent can be billed, which was not previously possible (according to the previous specifications, only a portion of the service actually rendered was reimbursed, for example, approx. $30 \%$ to the University Hospital of Cologne). 9) Advance care planning with individual consulting on hospice and palliative care issues will be funded.

\section{Neuropalliative Care Approaches and Concepts in the Literature}

Approximately $70 \%$ of neurological diseases have a chronic course often with progressive impairments. These diseases are known as long-term neurological conditions (LTNC) and include e. g., the following: MS, idiopathic and atypical Parkinson's syndrome, ALS, and Huntington's disease. Treating these patients mainly involve symptom control stabilization of neurological status and maintaining quality of life [41,42]. These treatment goals illustrate how important it is for different medical disciplines such as neurology, rehabilitative medicine, and palliative care to work together in order to holistically care for these incurably ill patients. In Great Britain it was demonstrated that complementary care concepts improve long-term results for patients and significantly reduce treatment costs $[43,44]$. Whereas the term "neuropalliative rehabilitation" is becoming established internationally [45-47], in Germany this is not yet the case. Here, palliative care is often "reserved" for endof-life care, especially for oncological patients [21]. In Great Britain, the "End of life care in long term neurological conditions - a framework for implementation" (NEoLCP) [48]) specifically recommends a multidisciplinary approach to care. This approach makes clear how the expertise of the various disciplines can be applied in an integrated way: Neurologists and neurorehabilitation physicians have extensive current knowledge on the specific characteristics of neurological diseases, including disease-specific treatment options and the associated odds and risks. They understand the possibilities of multidisciplinary rehabilitation programs and how they can be used to stabilize and improve neurological functions. The palliative care approach for these diseases particularly focuses on improving quality of life by relieving debilitating symptoms from a psychosocial, spiritual medical, and nursing standpoint. It addresses advanced care planning to be put in place as early as possible in the course of the disease, changes in treatment goals or end-of-life decisions. It is especially important to include family members, one part of the so-called "unit of care", in these proceses because communication is often limited in neurological patients and family members themselves often require a good deal of support and relief. This need results from the chronicity of many neurological diseases, which may be associated with changes in cognition, emotionality, and personality, thus placing extraordinary physical and emotional strain not only on the patients but also the caregiving family members. Palliative care typically involves a multidisciplinary team supported by different sectors (inpatient, outpatient). As family doctors or primary care physicians, general practitioners know their patients, their life circumstances, and their individual needs based on years or even decades of contact. They can therefore assess the patient's everyday reality quite well and bring that knowledge to bear in the treatment concept. As primary treating physicians, it is they in particular who must integrate the palliative care approach early on in the treatment process and make aware of palliative and hospice care services. Each area of expertise and the perspectives cited are significant in the care of neurological patients. However, in order to improve the reality of care, complementary approaches must be applied in an integrative way in treating these patients as recommended in NEoLCP [48]. Higher-level 
coordination processes, e. g., in form of a neuropalliative care nurse as described in the NEoLCP, proved especially helpful particularly in shaping the final year of life [49]. In Great Britain, a complementary short-term (12 week) intervention by neurologically trained, specialized outpatient palliative teams proved useful for seriously ill MS patients in a clinical phase II study [50-52]. Pain, nausea and vomiting, mouth problems and sleep disturbances significantly improved. Hospital stays were reduced and cost efficacy improved. Furthermore, the intervention provided relief for family members [50-52]. A randomized controlled confirmational clinical trial in Great Britain is currently testing a palliative care short-term intervention for MS and other LTNC such as ALS and Parkinson's syndrome (OPTCARE NEURO, Prof. I. Higginson, Cicely Saunders Institute, King's College London). In Italy, a randomized control pilot study (NE-PAL) demonstrated that the use of a specialized outpatient palliative care team alleviated symptoms (pain, respiratory distress, sleep disturbances bladder problems) in seriously ill patients with MS, ALS, (atypical) Parkinson's syndromes and improved their quality of life [53]. In patients with glioblastoma, a multidisciplinary outpatient team specially trained in neuro-oncology helped to stabilize the at-home care situation, resulting in fewer hospital admissions and allowing patients to die at home. Here, too, costs were reduced [54]. To date, no such intervention studies have been performed in Germany. However, with the aid of a Delphi survey of experts, criteria were defined [55] as to when and in what form palliative care (GPC/SPC) should be initiated in the care of MS patients. Criteria included the EDSS score, the onset of treatment with mitoxantrone, the initial use of treatment aids, transfer to a nursing home, or onset of severe palliative care symptoms as measured by HOPE, such as pain, nausea, vomiting, lack of appetite and constipation $[56,57]$.

\section{Considerations to Improve The Care of Neurological Patients with Palliative Care Needs}

Because there are usually less distinct disease trajectories in neurological illnesses, it is more difficult than in oncological diseases to define when to start with the palliative care approach or call upon the assistance of palliative and hospice care structures to care for neurologically ill patients $[21,22,58]$. Disease courses of the diverse progressive LTNC must be studied in order to determine what signs point to a poor prognosis and what complications will arise toward the end of life. Possible signs of a poor prognosis for patients with LTNC appear to be: dysphagia, aspiration pneumonia, recurring infections, and significant worsening of physical condition [27]. These general indications need to be studied and specified for the various neurological disease entities [55]. The so-called "surprise question" ("Would I be surprised if this patient died in the next 12 months?" [59,60]) has proved helpful in estimating the 12month survival probability of patients with oncological or nephrological diseases $[59,60]$. If this might be true also for neurological diseases still needs to be clarified. If it succeeds to better describe the disease trajectories of neurological diseases and thus recognizing poor prognoses earlier, the second stage can be used to define SOP similar to those for oncology patients [34] as to when to inte- grate palliative care in a general or specialized form in the treatment of these patients.

Implementing the palliative care approach in the care of neurological patients requires common development processes on both the neurological and palliative care sides: Occupational groups working in neurology need to be sensitized to palliative care issues, and those working in palliative care must endeavor to raise awareness of the palliative care needs of non-cancer patients. Joint training courses for neurologists and palliative care physicians at the regional level as well as at national and international conferences would be helpful. Another approach would be to give assistant physicians the opportunity to complete some of their advanced neurology training in palliative care units. Likewise, palliative care personnel (e.g., nurses, physicians) should be given the opportunity to work a rotation interval in a neurology department.

Based on international studies [49-54] and the authors' clinical experience, it is necessary to expand especially outpatient and most importantly at-home care structures to provide palliative care to neurological patients. Because seriously ill patients requiring palliative care are usually no longer able to seek out the required services and healthcare structures themselves, outreach services must be strengthened in particular. These include the services of various specialists such as neurologists, in cooperation with palliative care physicians/palliative care services if at all possible, as well as psychotherapists, social workers, physical therapists, speech therapists, etc. Patients and their caregiving relatives quite often express their desire to be relieved of time-consuming coordination processes [9] because they themselves cannot (or can no longer) do so. Patients and family members often lack the knowledge of what medical (including palliative care), nursing, co-therapeutic, hospice, psychosocial, social care and financial aids/services are basically available to them. Furthermore, establishing appropriate individual coordination centers to provide cross-sector case management would be helpful in order to use existing healthcare structures sufficiently and in an integrated way. To date, approaches that point in this direction have barely been addressed in the literature on patients with neurological diseases $[30,61,62]$. Coordination centers could help to consistently document exactly when problems cannot be addressed through existing healthcare structures and where there are gaps in the care of these patients that could be closed by taking steps to modify existing healthcare structures or create new ones. For example, the form of existing care structures including palliative and hospice care structures could be adapted to be more adequately prepared for the disease conditions and courses of neurologically ill patients. Because these diseases are chronic and sometimes progress in phases, other admissions and invoicing criteria are necessary than for oncology patients. Until now, insurers have covered outpatient hospice care services only for end-of-life support of patients with incurable, progressive, and far advanced illnesses. Such support care can be reimbursed only after death regardless of how long care was rendered. If outpatient hospice care services were to treat more chronically ill neurology patients, the very different disease courses would make rendering such care financially untenable. The prerequisites for reimbursement of outpatient hospice care services according to $§ 39$ a SGBV must be modified such that outpatient hospice care services can bill prior to the death of the patient should the patient require chronic or in- 
termittent hospice care. Children receiving palliative and hospice care often have chronic, progressive metabolic illnesses or neurological diseases in addition to oncology diseases. Unlike in adult care, pediatric care systems are better suited to treat chronic disease courses. In pediatric hospices, for example, it is possible to temporarily admit ill children to provide respite care, i. e., relieve caregiving family members [63]. Such options would certainly be helpful in the care of adult neurological patients. Thus far, respite care has not been addressed. Instead, admission into an adult hospice is linked to a life expectancy "of days, weeks or a few months - and for children, years" [64]. The exception for children described here should also be made for chronically ill adults such as those with neurological diseases. A special problem arises particularly after patients reach the age of 18 and are no longer eligible to receive the same level of care. Adults with neurological diseases, however, do frequently have long life expectancies with continual or at times severe symptoms and should therefore receive palliative and hospice care during the course of their incurable progressive disease. At-home care is especially problematic. Outpatient homecare is often no longer possible once the illness has reached a certain stage: the over long time periods (months to years) increased or persistent physical impairments and the associated inability to provide adequate self-care makes independent living impossible. Moreover, at some point, caregiving family members and friends can no longer provide care (strain too great, financial hardships due to absence from work, etc.) and reimbursement limits for nursing care (SGB XI) and in-home care services ( $\$ 37$ SGB V) are exceeded. It remains to be seen whether the current changes to the eligibility requirements for services under the nursing care classifications, namely extending the 3 former levels to 5 , will have an effect on this patient group. One welcome change is that limitations in activities of daily living will play a greater role. It is doubtful that the special focus of this limitation on mental and psychological causes will help neurological patients. In ALS, for example, cognitive abilities remain intact for a long time and the physical abilities to pursue activities of daily living decline more rapidly. More intensive nursing care as part of in-home care per $\S 37$ SGB $\vee$ up to roundthe-clock, "one-to-one presence" of qualified care professionals is covered by the insurance funds as outpatient intensive care as part of in-home nursing care only under certain conditions, e. g., invasively ventilated patients. This type of care option is rarely available for other severely impaired patients with serious symptoms, e. g., ALS patients with shortness of breath, marked sialorrhea, dysphagia, difficulty communicating, etc., who are neither ventilated nor wish to be so. For these patients consideration for such care requires an expensive and lengthy review of the individual case that the family members let alone the patient cannot afford, and the outcome is unclear. The prerequisite for outpatient intensive care per $\S 37$ SGB V must be expanded to include these patients. Patients with advanced neurological diseases are often only left with the option of receiving care in a nursing home. Nursing home care can be problematic because these facilities are usually specialized in caring for the elderly and not patients with complex neurological conditions, who are often young or middle-aged with severe symptoms and require complex assistance (e.g., communication aids, ventilation systems, cough-aasists). Although their numbers are increasing, there are still few specialized residential communi- ties (e. g., for ventilated patients ) or specialized nursing homes for patients with complex neurological diseases (e. g., including for younger MS sufferers) that offer adequate care. These facilities often lack the necessary specialized expertise in palliative care (medical/nursing) if a complementary consulting per $\S \S 37 \mathrm{~b} / 132 \mathrm{~d}$ SGB V (SOPC) might not be available.

Appropriate healthcare research must be conducted to better substantiate where gaps in care exist and how they can be closed. To this end, palliative care research (healthcare research, clinical trials) must be intensified. This is especially true for Germany which clearly falls behind in the intenational comparison, e. g., to Great Britain with respect to healthcare research and clinical trials in palliative care (see above). To respond to this need, the Federal Ministry for Education and Research (BMBF) issued a call for funding proposals for research into issues of palliative care in 2016.

\section{Conclusion}

Approximately $10 \%$ of neurological patients are estimated to have palliative care needs. In specialized palliative and hospice care structures, approximately $80 \%$ of patients are oncology patients, whose symptoms, needs, and disease trajectories tend to differ from those of neurological patients. This requires to some extent a structural modification of palliative and hospice care structures, which should basically be available to all patients with palliative care needs regardless of their primary illness. Furthermore, the expertise in the various disciplines (e. g., neurology, neurorehabilitation, palliative care, general medicine) needs to be applied in an integrated way to render adequate care to neuropalliative patients, with special consideration given to in-home care services. Intervention studies of neuropalliative care concepts are currently conducted in Great Britain, whereas those studies are lacking in Germany, so far.

\section{Conflict of interest}

No conflict of interest has been declared by the authors.

References

[1] Golla H, Ebke M, Rolke R et al. Integration von Palliativ- und Hospizstrukturen in die Versorgung Neurologischer Patienten - Meinungsbild neurologischer Chefärzte in Deutschland. Fortschr Neurol Psychiatr 2016; 84: 733-738

[2] World Health Organisation (WHO). Definition of palliative care. Im Internet: http://www.who.int ; (Abrufdatum: 28.07.2016)

[3] Hospiz- und Palliativerfassung (HOPE). HOPE-Bericht 2015. Im Internet: https://www.hope-clara.de (Abrufdatum: 28.07.2016)

[4] Statistisches Bundesamt. Die 10 häufigsten Todesursachen insgesamt - Sterbefälle nach der ICD $10 \mathrm{im}$ Jahr 2014. Im Internet: https://www. destatis.de (Abrufdatum: 23.09.2016)

[5] Scalfari A, Knappertz V, Cutter G et al. Mortality in patients with multiple sclerosis. Neurology 2013; 81: 184-192 
[6] Macleod AD, Taylor KS, Counsell CE. Mortality in Parkinson's disease: A systematic review and meta-analysis. Mov Disord 2014; 29 : 1615-1622

[7] Wolf J, Safer A, Wöhrle JC et al. Factors predicting one-year mortality in amyotrophic lateral sclerosis patients - data from a population-based registry. BMC Neurol 2014; 14: 197

[8] Higginson IJ, Hart S, Silber E et al. Symptom prevalence and severity in people severely affected by multiple sclerosis. J Palliat Care 2006; 22: 158-165

[9] Golla H, Galushko M, Pfaff H et al. Unmet needs of severely affected multiple sclerosis patients: The health professionals' view. Palliat Med 2012; 26: 139-151

[10] Basedow-Rajwich B, Koehler J. Besonderheiten der neuropalliativmedizinischen Versorgung schwerst betroffener MS-Patienten. Akt Neurol 2015; 42: 11-15

[11] Lorenzl S, Nubling G, Perrar KM et al. Palliative treatment of chronic neurologic disorders. Handb Clin Neurol 2013; 118: 133-139

[12] Hensler M, Paul S, Abright C et al. Progressive supranuclear palsy: Living environment of the patients in Germany. Nervenarzt 2011; 82: 207-214

[13] Lorenzl S. Multimorbidity of neurological patients in palliative care units. Nervenarzt 2014; 85: 409-416

[14] Grehl T. Diagnostics and therapy for amyotrophic lateral sclerosis. Fortschr Neurol Psychiatr 2013; 81: 592-603

[15] Oliver DJ, Campbell C, O'brien T et al. Medication in the last days of life for motor neuron disease/amyotrophic lateral sclerosis. Amyotroph Lateral Scler 2010; 11: 562-564

[16] Ostgathe C, Alt-Epping B, Golla $\mathrm{H}$ et al. Non-cancer patients in specialized palliative care in Germany: What are the problems? Palliat Med 2011; 25: 148-152

[17] Golla H, Ale Ahmad M, Galushko M et al. Glioblastoma multiforme from diagnosis to death: A prospective, hospital-based, cohort, pilot feasibility study of patient reported symptoms and needs. Support Care Cancer 2014; 22: 3341-3352

[18] Oberndorfer S, Lindeck-Pozza E, Lahrmann $\mathrm{H}$ et al. The end-of-life hospital setting in patients with glioblastoma. J Palliat Med. 2008; 11: 26-30

[19] Thier K, Calabek B, Tinchon A et al. The last 10 days of patients with glioblastoma: Assessment of clinical signs and symptoms as well as treatment. Am J Hosp Palliat Care 2016; 33: 985-988

[20] Ostgathe C, Gaertner J, Kotterba M et al. Hospice and palliative Care Evaluation (HOPE) Working Group in Germany. Differential palliative care issues in patients with primary and secondary brain tumours. Support Care Cancer 2010; 18: 1157-1163

[21] Golla H, Galushko M, Pfaff H et al. Multiple sclerosis and palliative care - Perceptions of severely affected multiple sclerosis patients and their health professionals: A qualitative study. BMC Palliat Care 2014; 13: 1

[22] Mcllfatrick S. Assessing palliative care needs: Views of patients, informal carers and healthcare professionals. J Adv Nurs 2007; 57: 77-86

[23] Kierner KA, Gartner V, Bartsch R et al. Attitudes towards palliative care in primary metastatic cancer: A survey among oncologists. Wien Klin Wochenschr 2010; 122: 45-49

[24] Kümpfel T, Hoffmann LA, Pöllmann W et al. Palliative care in patients with severe multiple sclerosis: Two case reports and a survey among German MS neurologists. Palliat Med 2007; 21: 109-114

[25] Voltz R. Palliative care for multiple sclerosis: A counter-intuitive approach? Mult Scler 2010; 16: 515-517

[26] Stolberg M. Die Geschichte der Palliativmedizin. Medizinische Sterbebegleitung von 1500 bis heute. Frankfurt a. M.: Mabuse Verlag; 2011

[27] Oliver D, Silber E. End of life care in neurological disease. In: Oliver D. (ed.). End of life care in neurological disease. London: Springer; 2012
[28] Ärztinnen nach Bezeichnungen und Tätigkeitsarten, Tabelle 4, Blatt 5. Im Internet: http://www.bundesaerztekammer.de/fileadmin/user_upload/downloads/pdf-Ordner/Statistik2015/Stat15AbbTab.pdf (Abrufdatum: 03.10.2016)

[29] Knies AK, Golla H, Strupp J et al. A palliative care hotline for multiple sclerosis: A pilot feasibility study. Palliat Support Care 2015; 13 : 1071-1078

[30] Funke A, Grehl T, Großkreutz J et al. Provision of assistive devices in amyotrophic lateral sclerosis. Analysis of 3 years case management in an internet-based supply network. Nervenarzt 2015; 86: 1007-1017

[31] Temel JS, Greer JA, Muzikansky A et al. Early palliative care for patients with metastatic non-small-cell lung cancer. N Engl J Med 2010; 363: 733-742

[32] Bakitas MA, Tosteson TD, Li Z et al. Early versus delayed initiation of concurrent palliative oncology care: Patient outcomes in the ENABLE III randomized controlled trial. J Clin Oncol 2015; 33: 1438-1445

[33] Zimmermann C, Swami N, Krzyzanowska M et al. Early palliative care for patients with advanced cancer: A cluster-randomised controlled trial. Lancet 2014; 383: 1721-1730

[34] Gaertner J, Wolf J, Hallek M et al. Standardizing integration of palliative care into comprehensive cancer therapy - a disease specific approach. Support Care Cancer 2011; 19: 1037-1043

[35] Leray E, Yaouang J, Le Page E et al. Evidence for a two-stage disability progression in multiple sclerosis. Brain 2010; 133 ((Pt7)): 1900-1913

[36] Arbeitsgemeinschaft der Wissenschaftlichen Medizinischen Fachgesellschaften e.V. (AWMF), Deutschen Krebsgesellschaft e.V. (DKG), Deutsche Krebshilfe. Leitlinien-Programm für Onkologie: S3-Leitlinie Palliativmedizin für Patienten mit einer nicht heilbaren Krankheit. Im Internet: http://www.awmf.org (Abrufdatum: 02.10.2016)

[37] Richtlinie des gemeinsamen Bundesausschusses zur Verordnung von spezialisierter ambulanter Palliativversorgung. Im Internet: https:// www.g-ba.de/downloads/62-492-437/SAPV-RL_2010-04-15.pdf (Abrufdatum: 05.10.2016)

[38] Empfehlungen des GKV Spitzenverbandes nach §132d Abs. 2 SGB V für die spezialisierte ambulante Palliativversorgung. Im Internet: https:// www.gkv-spitzenverband.de/media/dokumente/krankenversicherung_1/hospiz_palliativversorgung/Palliativ_Empfehlungen_nach_132d_Abs_2_SGB_V_05-11-20102.pdf (Abrufdatum: 05.10.2016)

[39] Gesetz zur Verbesserung der Hospiz- und Palliativversorgung in Deutschland (Hospiz- und Palliativgesetz - HPG). Im Internet: http:// www.bgbl.de/xaver/bgbl/start.xav?startbk = Bundesanzeiger_BGBI\#_ bgbl__\%2F\%2F*[\%40attr_id\%3D\%27bgbl115s2114. pdf\%27]__1455177642383 (Abrufdatum: 05.10.2016)

[40] Rahmenvereinbarung nach § 39a Abs. 2 Satz 8 SGB V zu den Voraussetzungen der Förderung sowie zu Inhalt, Qualität und Umfang der ambulanten Hospizarbeit. Im Internet: https://www.gkv-spitzenverband.de/media/dokumente/krankenversicherung_1/hospiz_palliativversorgung/Rahmenvereinbarung_39a_Abs_2_Satz_8_SGB_V_ ambulante_Hospizarbeit.pdf (Abrufdatum: 05.10.2016)

[41] Barnes MP. Principles of neurological rehabilitation. J Neurol Neurosurg Psychiatry 2003; 74 (Suppl 4): iv3-iv7

[42] Department of Health (DH). The National Service Framework for Long-term Conditions (14.08.2016). Im Internet: https://www.gov.uk Stand: 14.08.2016

[43] Turner-Stokes L, Sykes N, Silber E.Guideline Development Group. Long-term neurological conditions: Management at the interface between neurology, rehabilitation and palliative care. Clin Med 2008; 8: 186-191

[44] Jackson D, McCrone P, Turner-Stokes L. Costs of caring for adults with long-term neurological conditions. J Rehabil Med 2013; 45: 653-661

[45] Turner-Stokes L, Sykes N, Silber E et al. From diagnosis to death: exploring the interface between neurology, rehabilitation and palliative care in managing people with long-term neurological conditions. Clin Med 2007; 7: 129-136 
[46] Wade DT, de Jong BA. Recent advances in rehabilitation. Br Med ] 2000; 320: 1385-1388

[47] Tookman AJ, Hopkins K, Scharpen-von-Heussen K. Rehabilitation in palliative medicine. In: Doyle D, Hanks G, Cherney N, Calman K. (eds.). Oxford Textbook of Palliative Medicine. 3rd ed. Oxford: Oxford University Press; 2004

[48] The National Council for Palliative Care. End of life care in long term neurological conditions: A framework for implementation (14.08.2016). Im Internet: https://www.mssociety.org.uk Stand: 14.08.2016

[49] Hussain J, Adams D, Campbell C. End-of-life care in neurodegenerative conditions: Outcomes of a specialist palliative neurology service. Int J Palliat Nurs 2013; 19: 162-169

[50] Higginson I], Hart S, Burman R et al. Randomised controlled trial of a new palliative care service: Compliance, recruitment and completeness of follow-up. BMC Palliat Care 2008; 7: 7

[51] Higginson I], McCrone P, Hart SR et al. Is short-term palliative care cost-effective in multiple sclerosis? A randomized phase II trial. J Pain Symptom Manag 2009; 38: 816-826

[52] Edmonds P, Hart S, Wei G et al. Palliative care for people severely affected by multiple sclerosis: Evaluation of a novel palliative care service. Mult Scler 2010; 16: 627-636

[53] Veronese S, Gallo G, Valle A et al. Specialist palliative care improves the quality of life in advanced neurodegenerative disorders: NE-PAL, a pilot randomised controlled study. BMJ Support Palliat Care 2015; 16 :

[54] Pace A, Di Lorenzo C, Capon A et al. Quality of care and rehospitalization rate in the last stage of disease in brain tumor patients assisted at home: a cost effectiveness study. J Palliat Med 2012; 15: 225-227

[55] Strupp J, Romotzky V, Galushko M et al. Palliative care for severely affected patients with multiple sclerosis: When and why? Results of a Delphi survey of health care professionals. J Palliat Med 2014; 17: 1128-1136

[56] Radbruch L, Nauck F, Ostgathe C et al. What are the problems in palliative care? Results from a representative survey. Support Care Cancer 2003; 11: 442-451
[57] Stiel S, Pollok A, Elsner F et al. Validation of the symptom and problem checklist of the German Hospice and Palliative Care Evaluation (HOPE). J Pain Symptom Manage 2012; 43: 593-605

[58] Wilson E, Seymour ], Aubeeluck A. Perspectives of staff providing care at the end of life for people with progressive long-term neurological conditions. Palliat Support Care 2011; 9: 377-385

[59] Pang WF, Kwan BC, Chow KM et al. Predicting 12-month mortality for peritoneal dialysis patients using the "surprise" question. Perit Dial Int 2013; 33: 60-66

[60] Moroni M, Zocchi D, Bolognesi D et al. The 'surprise' question in advanced cancer patients: A prospective study among general practitioners. Palliat Med 2014; 28: 959-964

[61] Wynia K, Annema C, Nissen $\mathrm{H}$ et al. Design of a Randomised Controlled Trial (RCT) on the effectiveness of a Dutch patient advocacy case management intervention among severely disabled Multiple Sclerosis patients. BMC. Health Serv Res 2003; 10: 142

[62] Young L, Healey K, Charlton M et al. A home-based comprehensive care model in patients with Multiple Sclerosis: A study pre-protocol. F1000Res 2015; 18: 872

[63] Champagne M, Mongeau S. Effects of respite care services in a children's hospice: The parents' point of view. J Palliat Care 2012; 28: 245-251

[64] Rahmenvereinbarung nach § 39a über Art und Umfang sowie Sicherung der Qualität der stationären Hospizversorgung vom 30.03.1998, i.d. F. vom 14.04.2014. Im Internet: http://www.dhpv.de/ tI_files/public/Service/Gesetze \%20und \%20Verordnungen/2009-07-23_RV-stationaer.pdf (Abrufdatum 10.02.2017) 